\title{
Efecto de factores abióticos en el crecimiento vegetativo de Alexandrium catenella proveniente de quistes en laboratorio
}

\author{
Effect of abiotic factors in vegetative growth of Alexandrium catenella \\ from cysts in laboratory \\ Marcela Avila ${ }^{1,2}$, Constanza De Zarate ${ }^{1,2}$, Alejandro Clement ${ }^{2}$, \\ Pamela Carbonell ${ }^{2}$ y Felipe Pérez ${ }^{2}$
}

\begin{abstract}
'Instituto de Ciencia y Tecnología ICYT. Universidad Arturo Prat, Ejercito \#443. Puerto Montt, Chile. mavila@unap.cl ${ }^{2}$ Corporación de Desarrollo de la Universidad Arturo Prat, CORDUNAP, Av. Playa Brava 3256, Iquique, Chile

Abstract.- Alexandrium catenella is a toxic dinoflagellate that causes harmful algal blooms in the marine inland sea of southern Chile. To gain an insight about the effect of temperature, salinity, photoperiod and nutrient levels in culture medium growth vegetative polyclonal cells of A. catenella (strain AC090610 QUE-Q) from sediment cysts (Quellón, Chile) were cultivated. The strain was studied in different experiments by cells count using the Utermöhl method, every 2 days during 56 days. Effect of salinity $(15,20,25,30)$ using as control seawater with 31 of salinity; temperature $\left(10,15\right.$ and $\left.20^{\circ} \mathrm{C}\right)$ photoperiod $(12: 12$, 16:08 and 8:16 L:D) and was determinated nutrients, with $\mathrm{L} 1$ medium at different proportions of $\mathrm{NaNO}_{3}$ and $\mathrm{NaHPO}_{4}$. The results showed that cells of $A$. catenella grew in all range of salinities tested, showing a greater growth rate at 30 (3788 cells $\mathrm{mL}^{-1}$ on day $\left.26 ; \mu=0.18 \mathrm{div} \mathrm{d}^{-1}\right)$. At $20^{\circ} \mathrm{C}$, temperature decrease the growth rate $\left(<1500\right.$ cells $\left.\mathrm{mL}^{-1} ; \mu=0.11 \mathrm{div} \mathrm{d}^{-1}\right)$ while at $10^{\circ} \mathrm{C}$ and $15^{\circ} \mathrm{C}$ stimulate the growth $\left(>3000\right.$ cells $\mathrm{mL}^{-1} ; \mu=0.12 \mathrm{div} \mathrm{d}^{-1}$ ). The culture medium without nitrates and phosphates inhibit

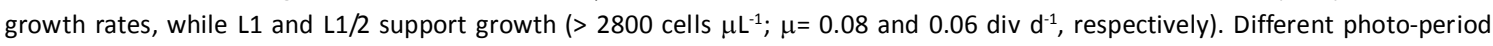
treatments have similar results $\left(\mu=0.05,0.07\right.$ and $\left.0.08 \mathrm{div} \mathrm{d}^{-1}\right)$ reaching 2000 cells $\mathrm{mL}^{-1}$ at the end of the experiment. These results suggest that the cultured strain responded to changes in temperature, photoperiod and different nutrient concentrations.
\end{abstract}

Key words: Alexandrium catenella, growth rate, temporal and dormant cysts, temperature, photoperiod, policlonal culture

Resumen.- La especie Alexandrium catenella es tóxica y causa floraciones algales nocivas en el mar interior del sur de Chile. Con el objetivo de evaluar el efecto de temperatura, salinidad, fotoperiodo y cantidad de nutrientes en el medio de cultivo, se iniciaron cultivos vegetativos de una cepa policlonal de A. catenella (cepa AC090610 QUE-Q) obtenidos de quistes de sedimentos (Quellón, Chile). La cepa fue utilizada en experimentos, montados en triplicado y contabilizados mediante el método Utermöhl cada 2 días durante 56 días. Se estudió el efecto de la salinidad $(15,20,25,30)$, utilizando como control agua de mar con 31 de salinidad; temperatura $\left(10,15\right.$ y $\left.20^{\circ} \mathrm{C}\right)$; fotoperiodo $(12: 12,16: 08$ y 8:16 L: 0$)$ y nutrientes con medio L1 con diferentes volúmenes de soluciones de $\mathrm{NaNO}_{3}$ y $\mathrm{NaHPO}_{4}$. Los resultados muestran que la cepa creció en todo el rango de las salinidades probadas, teniendo mayor crecimiento a 30 de salinidad (3788 células $\mathrm{mL}^{-1}$ el día $26 ; \mu=$ $\left.0,18 \mathrm{div} \mathrm{d}^{-1}\right)$. La temperatura de $20^{\circ} \mathrm{C}$ disminuye el crecimiento $\left(<1500\right.$ células $\left.\mathrm{mL}^{-1} ; \mu=0,11 \mathrm{div}^{-1}\right)$ mientras $10^{\circ} \mathrm{C}$ y $15^{\circ} \mathrm{C}$ favorecen el crecimiento $\left(>3000\right.$ células $\mathrm{mL}^{-1} ; \mu=0.12 \mathrm{div}^{-1}$ ). El medio de cultivo sin nitrato ni fosfato inhibe el crecimiento ( $<1000$ células $\left.\mathrm{mL}^{-1}\right)$, mientras que L1 y L1/2 favorecen el crecimiento $\left(\mu=0,08\right.$ y $0,06 \mathrm{div} \mathrm{d}^{-1}$, respectivamente) ( $>2800$ células $\left.\mathrm{mL}^{-1}\right)$. Los tratamientos de fotoperiodo tienen comportamiento similar $\left(\mu=0,05,0,07\right.$ y $\left.0,08 \mathrm{div} \mathrm{d}^{-1}\right)$ alcanzando las 2000 células $\mathrm{mL}^{-1}$ al final del experimento. Estos resultados indican que la cepa cultivada responde a cambios en temperatura, fotoperiodo y diferentes concentraciones de nutrientes.

Palabras clave: Alexandrium catenella, tasa de crecimiento, quiste de resistencia y temporal, temperatura, fotoperiodo, cultivo policlonal

\section{INTRODUCCIÓN}

Las Floraciones Algales Nocivas (FANs) o Mareas Rojas son eventos naturales que ocurren en la mayoría de los océanos del mundo (Lembeye 2006, Anderson et al. 2012). Guzmán et al. (1975a) señalan el primer registro de una floración tóxica en Chile para 1972, en la Región de Magallanes $\left(50^{\circ}\right.$ a $\left.54^{\circ} \mathrm{S}\right)$, causado por el dinoflagelado Alexandrium catenella, (Whedon \& Kofoid) Balech, 1985, agente biológico productor del Veneno Paralizante 
de Mariscos (VPM) (Guzmán et al. 1975b), principalmente derivados de saxitoxinas (Seguel et al. 2006). Posteriormente, la especie ha sido detectada en la Región de Aysén (42 a $50^{\circ} \mathrm{S}$ ) (Muñoz et al.1992) y observada por primera vez en muestras cualitativas en el extremo sur del Archipiélago de Chiloé (43으) en 1998 (Lembeye et al. 1998). Clément et al. (2002) ${ }^{1}$ registran una intensa floración de A. catenella de alta toxicidad (789 células $\mathrm{mL}^{-1}$ ), confirmando la distribución de floraciones de esta especie en el norte, desde los $42^{\circ} 10^{\prime} \mathrm{S}$ hasta los $45^{\circ} 47^{\prime} \mathrm{S}$, en la Región de Los Lagos. Fuentes et al. (2006) reportan la ocurrencia de una floración en el mar interior de la Región de Aysén en el verano del periodo 2005 y 2006, con abundancia máximas de 961 células $\mathrm{mL}^{-1}$, causando intoxicaciones humanas y una muerte, afectando además, la producción de salmónidos con mortalidades y daños a nivel de las agallas de los peces cultivados. Durante las últimas décadas se ha incrementado el número de estudios y reportes de presencia de células vegetativas de $A$. catenella en el plancton presente en la costa chilena, destacando como la floración más importante la del verano-otoño del 2009 (Mardones et al. 2010). Este evento ha sido descrito para una amplia zona geográfica desde los $43^{\circ} 45^{\prime} \mathrm{S}$ hasta los $46^{\circ} \mathrm{S}$, en marzo 2009 , alcanzando un máximo de 6000 células $\mathrm{mL}^{-1}$, generando decoloración, de color rojo y bioluminiscencia en el mar. En noviembre 2009 se reportó A. catenella más al norte aún, en las localidades de Cucao, Faro Corona, Mar Brava y Punta Bonita $\left(41^{\circ} 44^{\prime} \mathrm{S}\right)$ en el área de Calbuco (Mardones et al. 2010).

Dado que en el mar interior del sur de Chile se ha desarrollado la actividad acuícola de mitílidos y salmónidos, la presencia de A. catenella y sus toxinas representan una amenaza para la salud pública (Molinet et al. 2003), con impactos productivos y económicos en la pesca artesanal (Seguel et al. 2010a) y en la industria acuícola (Fuentes et al. 2006, Mardones et al. 2010), se hace necesario aumentar el conocimiento acerca de las condiciones ambientales que favorecen el crecimiento de esta especie.

Existen diversos estudios realizados en Chile que informan de floraciones de células vegetativas (Guzmán \& Lembeye 1975, Guzmán et al. 1975, Cassis et al. 2002, Molinet et al. 2003, Lembeye 2006, Fuentes et al. 2006, Mardones et al. 2010) y de la distribución de quistes de
A. catenella en sedimentos (Seguel et al. 2010a, b; Alvesde-Souza et al. 2008), demostrando presencia recurrente de este dinoflagelado en el mar interior del sur de Chile.

Varios estudios de laboratorio han analizado el efecto de la temperatura y la salinidad en la toxicidad y variabilidad genética de células de A. catenella (Navarro et al. 2006, Garrido \& Frangopulos 2012, AguileraBelmonte et al. 2011, 2013; Varela et al. 2012), así como también el efecto de nutrientes como nitrógeno y fósforo en el crecimiento (Garrido et al. 2012), perfiles de cistos y toxinas (Bustamante et al. 2003, Cox et al. 2008), cruzamientos y formación de quistes (Figueroa et al. 2005), ciclo de vida (Uribe et al. 2010), además de aspectos de biología molecular y análisis filogenético (Córdova \& Müller 2002, Varela et al. 2012).

A. catenella se caracteriza por presentar quistes de resistencia y quistes temporales en su ciclo de vida. Para los primeros se han descrito importantes roles ecológicos: 1) forman agregaciones que pueden iniciar una nueva floración algal; 2) constituyen un mecanismo de dispersión; 3) sobreviven en condiciones ambientales adversas y 4) permiten la recombinación genética cuando provienen de reproducción sexual (Figueroa et al. 2005; Seguel et al. 2010b). Es importante destacar, que los quistes temporales, que se originan a partir de una célula vegetativa, ocurren cuando la microalga enfrenta condiciones de estrés ambiental (Uribe et al. 2010).

Estudios de cultivo en laboratorio de cepas de $A$. catenella provenientes de la Región de Aysén y de Los Lagos (Navarro et al. 2006, Aguilera-Belmonte et al. 2013) han reportado una temperatura óptima de crecimiento de 12 y $15^{\circ} \mathrm{C}$, respectivamente, indicando que estos óptimos pueden variar dependiendo del origen de la cepa.

Si bien se han reportado resultados de factores y efectos en relación al crecimiento de células vegetativas aisladas desde floraciones algales, existe escasa información de las respuestas de cultivos provenientes de quistes de resistencia. El objetivo general del presente estudio fue evaluar bajo condiciones de laboratorio, el efecto de factores como temperatura, salinidad, fotoperiodo y cantidad de nutrientes en el crecimiento de células vegetativas de $A$. catenella, obtenidas desde quistes de sedimentos. 


\section{Materiales Y MÉTODOS}

\section{ÁREA DE MUESTREO Y OBTENCIÓN DE QUISTES}

Se seleccionó un área de muestreo en el sector de Punta Yenecura, zona Sur de Quellón (430' 44,2 ''S; 73³9’30,6”W), Región de Los Lagos, Chile (Fig. 1), para colectar quistes de Alexandrium catenella desde el sedimento superficial. Las muestras de sedimento fueron colectadas durante el verano del 2010 (FONDEF MR07 I1010), mediante un muestreador de fondo $\mathrm{KC}$ haps (KCDenmark) con un tubo de muestra de policarbonato (13,3 $\mathrm{cm}$ DI; área de muestreo $127 \mathrm{~cm}^{2}$ ). En cada sitio de muestreo, sobre la embarcación, una vez colectados los testigos de sedimento, se procedió a seccionarlos en su totalidad cada $1 \mathrm{~cm}$ de profundidad, desde la superficie hasta el fondo, guardando las muestras en frío $\left(4^{\circ} \mathrm{C}\right)$ y oscuridad hasta ser procesadas en frascos plásticos de $250 \mathrm{cc}$ y transportados al laboratorio de Algas del Instituto de Ciencia y Tecnología de la Universidad Arturo Prat en Puerto Montt.
Los quistes fueron aislados de sedimento proveniente de los primeros $3 \mathrm{~cm}$ de profundidad e incubados en placas de cultivo de tejidos tipo micropocillo (1 mL) (Nunc) utilizando la técnica descrita por Matsuoka \& Fukuyo (2000) e incubados con medio de cultivo L1 (Guillard \& Hargraves 1993), en condiciones controladas de temperatura $\left(15^{\circ} \mathrm{C}\right)$, fotoperiodo (16:08 luz:oscuridad) e intensidad de luz $\left(24-26 \mu \mathrm{mol} \cdot \mathrm{m}^{-2} \cdot \mathrm{s}^{-1}\right)$. Después de liberadas las células del quiste, estas fueron aisladas y dispuestas en placas con micropocillos para su cultivo, en las mismas condiciones antes mencionadas.

\section{Cultivo vegetativo en laboratorio}

Se realizaron estudios del efecto sobre el crecimiento de esta cepa, de factores como salinidad, temperatura, fotoperiodo y nutrientes. Para esto, se mantuvieron todas las condiciones fijas con excepción del parámetro abiótico a evaluar. En todos los casos, las células de los cultivos fueron aclimatadas a la nueva condición durante 7 días, antes de iniciar el experimento en triplicado, en matraces $74^{\circ} 0^{\prime} 0 " \mathrm{~W}$

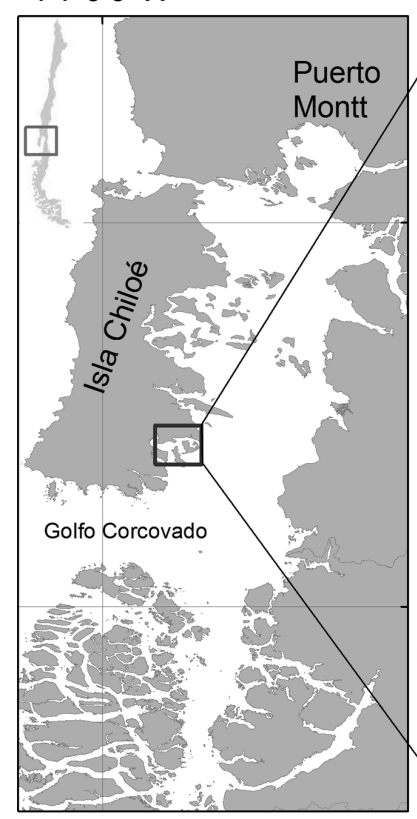

$73^{\circ} 35^{\prime} 0^{\prime \prime} \mathrm{W}$

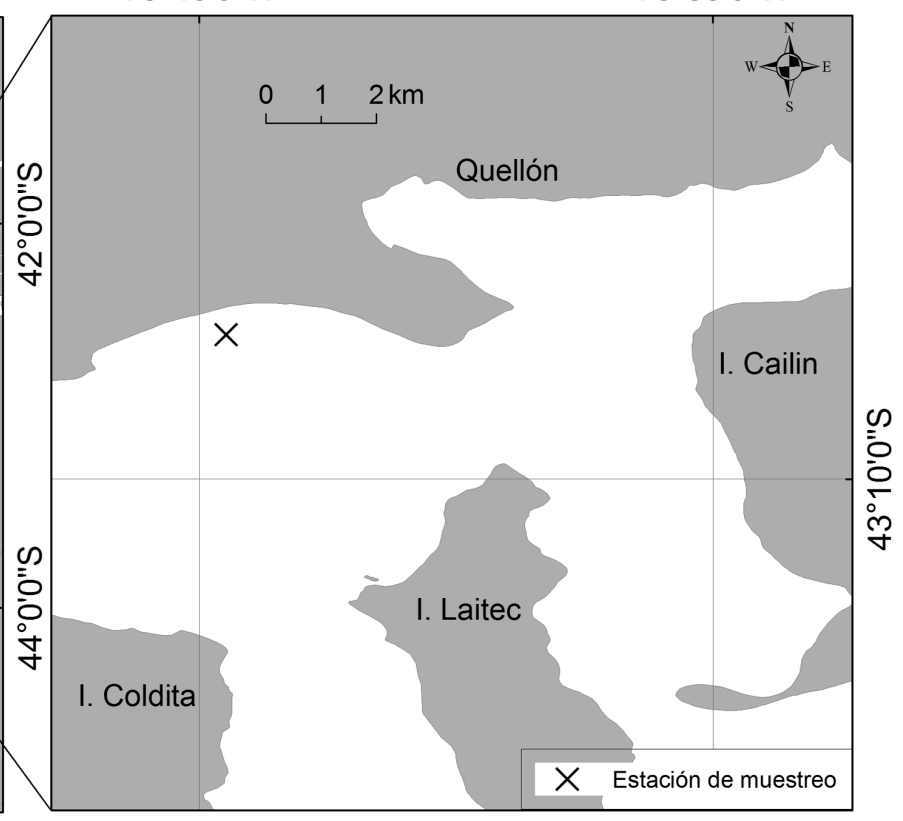

Figura 1. Localización de la estación de muestreo de los sedimentos. Origen de la cepa AC090610 QUE-Q

/ Location of the bottom sediment sampling station. Origin of the strain AC090610 QUE-Q 
Erlenmeyer de $500 \mathrm{~mL}$. Para evaluar el efecto de la variable salinidad, los niveles fueron 15, 20, 25 y 30, utilizando agua de mar de salinidad 31 como control; la temperatura se evaluó a 10,15 y $20^{\circ} \mathrm{C}$, considerando $10^{\circ} \mathrm{C}$ como el control, ya que corresponde a la temperatura media de $10,5^{\circ} \mathrm{C}$ del lugar de origen de la cepa durante el año (Carrasco \& Silva 2008). Los distintos fotoperiodos probados fueron 12:12, 16:08 y 08:16 (luz: oscuridad). En este caso no se consideró un control, puesto que los fotoperiodos usados simularían diferentes estaciones del año. Por último, se evaluó el efecto nutrientes en 6 tratamientos, utilizando como base agua de mar esterilizada: a) adición de nitratos $\left(\mathrm{NaNO}_{3}\right)$ y fosfatos $\left(\mathrm{Na}_{2} \mathrm{HPO}_{4} \mathrm{x} \mathrm{H}_{2} \mathrm{O}\right) \mathrm{L} 1$; b) adición de nitratos $\left(\mathrm{NaNO}_{3}\right)$ y fosfatos $\left(\mathrm{Na}_{2} \mathrm{HPO}_{4} \times \mathrm{H}_{2} \mathrm{O}\right) \mathrm{L1} / 2$; c) adición de nitratos $\left(\mathrm{NaNO}_{3}\right)$ y fosfatos $\left.\left(\mathrm{Na}_{2} \mathrm{HPO}_{4} \times \mathrm{H}_{2} \mathrm{O}\right) \mathrm{L} 1 / 10 ; \mathrm{y} \mathrm{d}\right)$ adición de nitratos $\left(\mathrm{NaNO}_{3}\right)$ y fosfatos $\left(\mathrm{Na}_{2} \mathrm{HPO}_{4} \times \mathrm{H}_{2} \mathrm{O}\right) \mathrm{L} 1 / 15$; e) tratamiento sin nitratos ni fosfatos, L1 S/N-P. En todos los casos anteriores, se adicionó $1 \mathrm{~mL}$ de solución de metales en traza y $0,5 \mathrm{~mL}$ de solución de vitaminas (Tabla 1); f) el tratamiento control consistió en agua de mar esterilizada sola (Tratamiento control).

Las distintas salinidades se obtuvieron adicionando agua destilada en base a la fórmula:

$$
\mathrm{V}_{1} \times \mathrm{C}_{1}=\mathrm{V}_{2} \times \mathrm{C}_{2}
$$

donde; $\mathrm{V}_{1}$ corresponde al volumen de medio de cultivo $\mathrm{L} 1 \mathrm{y} \mathrm{V}_{2}$ el volumen de agua destilada agregada hasta lograr la salinidad. $\mathrm{C}_{1}$ es la salinidad del agua de mar (control) y $\mathrm{C}_{2}$ la salinidad que se desea obtener.

Tabla 1. Tratamientos de nutrientes. Concentración de nitrato de sodio $\left(\mathrm{NaNO}_{3}\right)$ y fosfato sódico $\left(\mathrm{NaH}_{2} \mathrm{PO}_{4}\right)$. (*) Incluye solución de metales traza y solución de vitaminas según Guillard \& Hargraves 1993. (**) Sin solución de metales traza y solución de vitaminas / Nutrient treatments. Concentration of sodium nitrate $\left(\mathrm{NaNO}_{3}\right)$ and sodium phosphate $\left(\mathrm{NaH}_{2} \mathrm{PO}_{4^{\prime}}\right) .\left({ }^{*}\right)$ Includes solution trace metals and vitamin solution according to Guillard \& Hargraves 1993. $\left({ }^{* *}\right)$ No solution trace metals and vitamin solution is included

\begin{tabular}{lll}
\hline Tratamientos & $\begin{array}{l}\mathrm{NaNO}_{3} \\
\left(\mathrm{~m} \mathrm{~L}^{-1}\right)\end{array}$ & $\begin{array}{c}\mathrm{NaH}_{2} \mathrm{PO}_{4} \\
\left(\mathrm{~m} \mathrm{~L}^{-1}\right)\end{array}$ \\
\hline $\mathrm{L} 1$ & 0,880 & 0,036 \\
$\mathrm{~L} 1 / 2$ & 0,440 & 0,018 \\
$\mathrm{~L} 1 / 10$ & 0,088 & 0,004 \\
$\mathrm{~L} 1 / 15$ & 0,0587 & 0,0024 \\
$\mathrm{~L} 1 \mathrm{~S} / \mathrm{N}-\mathrm{P}\left(^{*}\right)$ & 0 & 0 \\
Control $(* *)$ & 0 & 0 \\
\hline
\end{tabular}

Las respuestas de A. catenella se evaluaron cuantificando la abundancia celular, determinando el número de células y calculando las tasas de crecimiento. La abundancia celular se determinó mediante el método Utermöhl (Utermöhl 1958) con una frecuencia de 2 veces por semana durante un periodo de 56 días. En cada muestreo se tomó una alícuota de $2 \mathrm{~mL}$ para las 3 réplicas, se fijó con lugol al 50\% y después de 1 h de decantación se realizó el conteo de células en un microscopio invertido. La tasa de crecimiento se calculó según Guillard (1973) en base a la ecuación siguiente.

$$
\mu=\frac{\ln \left(\frac{\mathrm{N} 1}{\mathrm{~N} 0}\right)}{(\mathrm{t} 1-\mathrm{t} 0)}
$$

donde, $\mu$ es la tasa de crecimiento, $\mathrm{N}$ el número de células en el cultivo (células $\mathrm{mL}^{-1}$ ), y t el tiempo en días.

Se analizaron los resultados de abundancia celular y tasas de crecimiento, mediante estadística paramétrica ANDEVA de una vía, con análisis posterior de Tukey, considerando los supuestos de normalidad y homogeneidad de varianza y estadística no paramétrica test de Kruskal-Wallis a través del programa STATISTIC Av. 7.0 (StatSoft, Inc.), considerando una probabilidad $P$ $<0,05$ para detectar diferencias estadísticas significativas (Zar 1999).

\section{Resultados}

Las células vegetativas provenientes de quistes de Alexandrium catenella crecieron en todas las salinidades probadas (Fig. 2), no obstante, se observó mayor crecimiento a 30 de salinidad (3788 células $\mathrm{mL}^{-1}$, día 26; $\left.\mu=0,18 \mathrm{div} \mathrm{d}^{-1}\right)$, y un menor crecimiento a 15 y $20 \mathrm{de}$ salinidad (2324 células $\mathrm{mL}^{-1} \mathrm{el}$ día 51 y 2018 células $\mathrm{mL}^{-1}$; $\mu=0,12 \mathrm{div} \mathrm{d}^{-1}$, respectivamente). Para la abundancia de células, se observó diferencias significativas entre 30 de salinidad respecto a 15 y $20(P<0,05)$ y 20 respecto a 25 . En cuanto a la tasas de crecimiento hubo diferencias significativas entre el control $\left(\mu=0,21 \mathrm{div} \mathrm{d}^{-1}\right)$ y aquellos tratamientos de 15 y 20 de salinidad.

Se observó crecimiento celular en todas las temperaturas probadas (Fig. 3), pero se registró mayor crecimiento a 10 y $15^{\circ} \mathrm{C}$ (>3000 células $\mathrm{mL}^{-1 ;} \mathrm{m}=0,08$ y 0,12 $\operatorname{div} \mathrm{d}^{-1}$ respectivamente). A $20^{\circ} \mathrm{C}$ se observó tasas de crecimiento bajas $\left(<1500\right.$ células $\left.\mathrm{mL}^{-1} ; \mathrm{m}=0,10 \mathrm{div} \mathrm{d}^{-1}\right) \mathrm{y}$ las células presentaron coeficientes de absorción específicos de clorofila $a$ bajos (Clément com. per). 

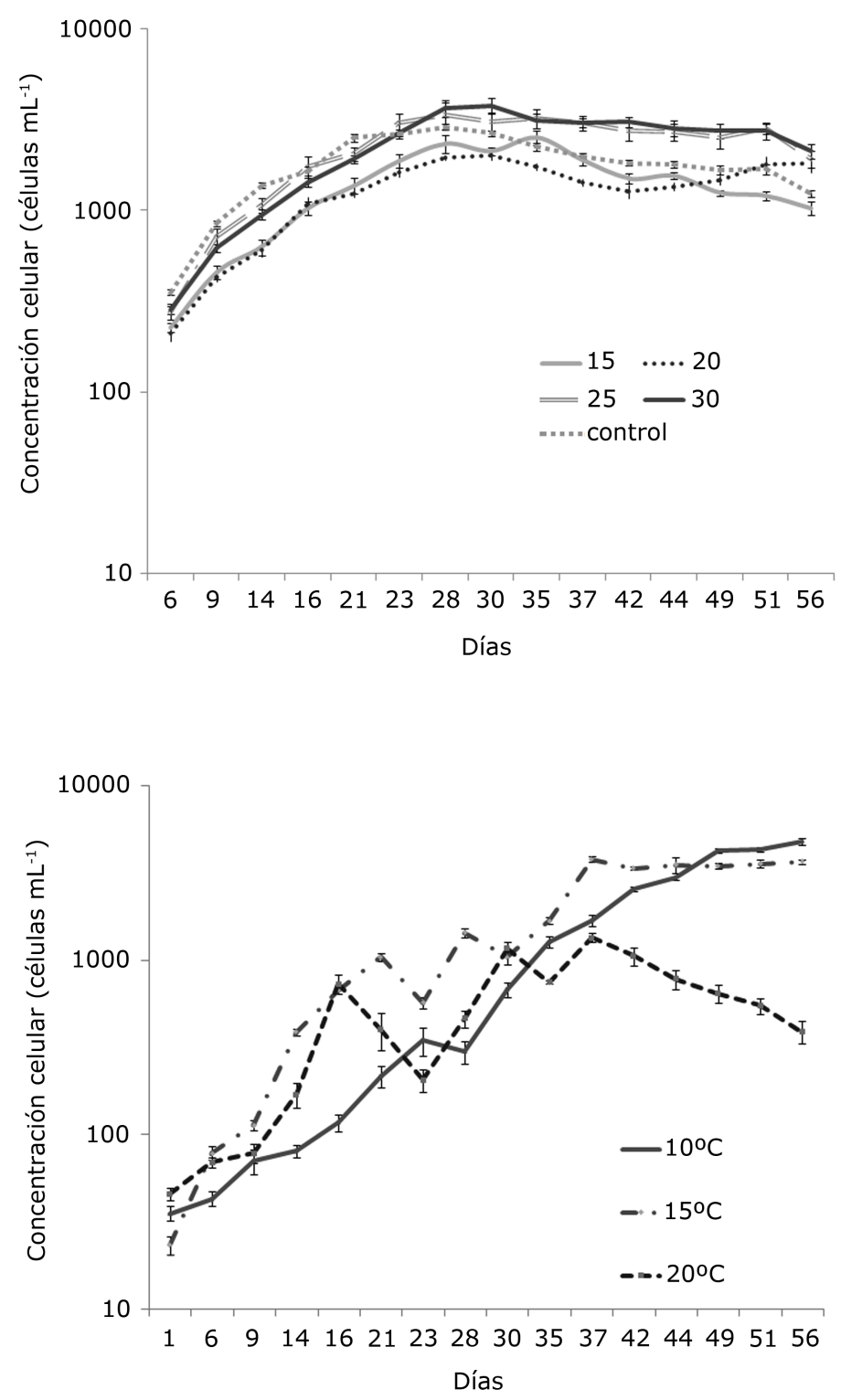

Figura 2. Crecimiento de Alexandrium catenella cultivada en 5 salinidades diferentes. Valores promedio de células $\mathrm{mL}^{-1} \pm \mathrm{D}$.E / Growth of Alexandrium catenella cultures at 5 different salinities. Mean values cells $\mathrm{mL}^{-1} \pm \mathrm{SD}$

Figura 3. Crecimiento de Alexandrium catenella cultivada en 3 temperaturas diferentes. Valores promedio de células $\mathrm{mL}^{-1} \pm \mathrm{D}$.E / Growth of Alexandrium catenella cultures at 3 different temperatures. Mean values cells $\mathrm{mL}^{-1} \pm \mathrm{SD}$
Los tratamientos de fotoperiodo tuvieron resultados similares entre ellos, alcanzando las 2000 células $\mathrm{mL}^{-1}$ al final del experimento (Fig. 4). No existieron diferencias significativas al comparar la concentración celular. En la estimación de tasas de crecimiento, si se observaron diferencias significativas entre los distintos fotoperiodos 12:12 (Luz: Oscuridad) ( $\left.\mu=0,05 \mathrm{div} \mathrm{d}^{-1}\right)$ respecto a los fotoperiodos 16:08 y 08:16 $\left(\mu=0,07 \operatorname{div~d}^{-1}\right)(P<0,05)$.
Los medios de cultivo L1 y L1/2 favorecieron el crecimiento de las células de $A$. catenella (>2800 células $\mathrm{mL}^{-1} ; \mu=0,08$ y $0,07 \mathrm{div} \mathrm{d}^{-1}$ respectivamente), mientras los tratamientos L1/10, L1/15 y L1 s/N-P no favorecieron el crecimiento $\left(<1000\right.$ células $\left.\mathrm{mL}^{-1} ; \mu=0,06 \mathrm{div} \mathrm{d}^{-1}\right)$, observándose ocasionalmente formación de quistes temporales. Existieron diferencias significativas en la concentración celular en los diferentes tratamientos $(P<$ $0,05)$ en la fase exponencial de la curva de crecimiento, no así, en la tasa de crecimiento (Fig. 5). 

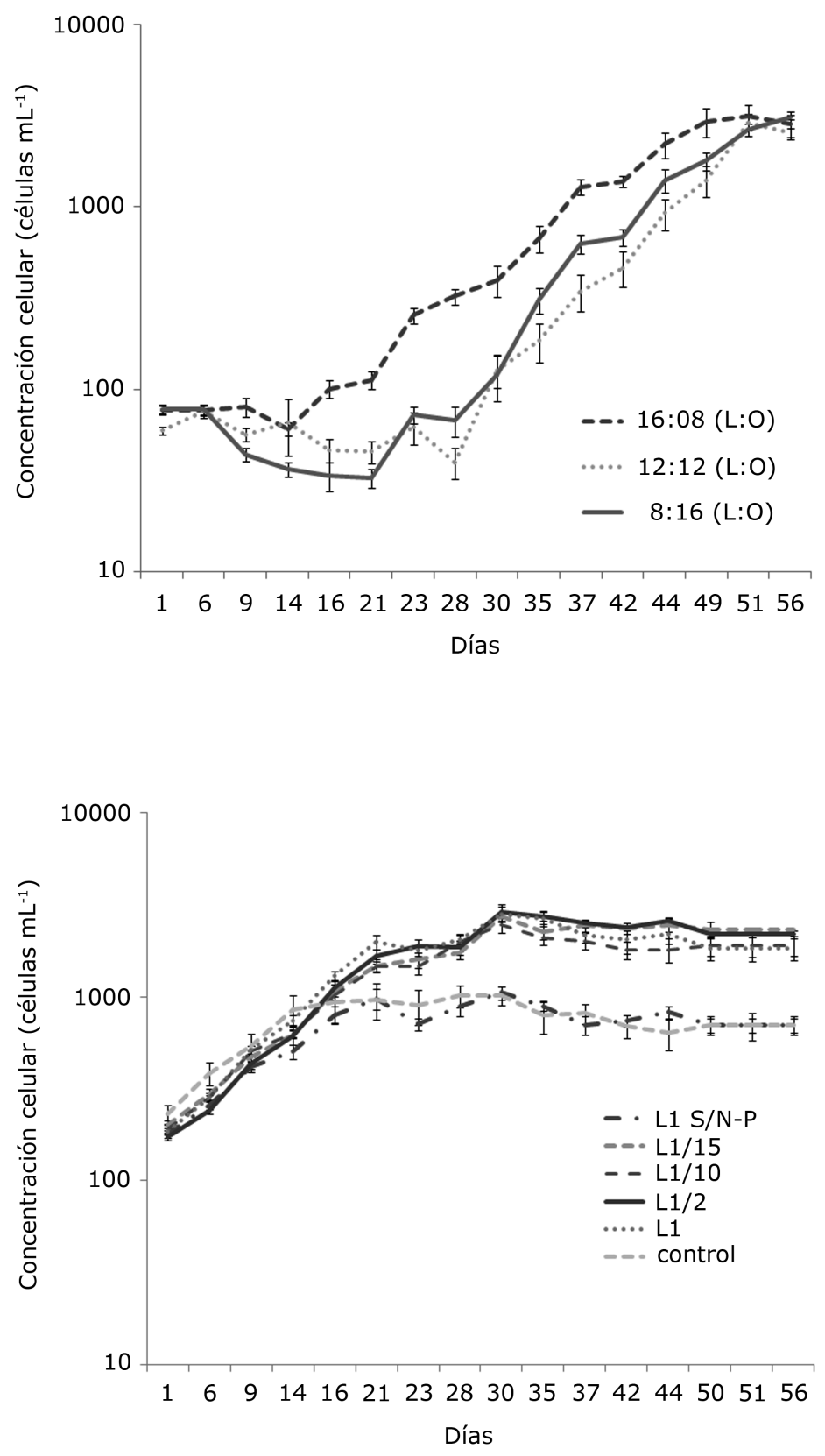

Figura 4. Crecimiento de Alexandrium catenella cultivada en 3 fotoperiodos diferentes. Valores promedio de células $\mathrm{mL}^{-1} \pm D$.E / Growth of Alexandrium catenella cultures at 3 different photoperiods. Mean values cells $\mathrm{mL}^{-1} \pm \mathrm{SD}$
Figura 5. Crecimiento de Alexandrium catenella cultivada en 6 tratamientos de nutrientes. Valores promedio de células $\mathrm{mL}^{-1} \pm$ D.E / Growth of Alexandrium catenella cultures at 6 different nutrient treatments. Mean values cells $\mathrm{mL}^{-1} \pm \mathrm{SD}$

\section{Discusión}

Los resultados demuestran que la cepa AC090610-QU-Q proveniente de quistes de sedimento de la especie Alexandrium catenella es capaz de aclimatarse a diferentes condiciones abióticas en laboratorio. La presencia de quistes bentónicos de resistencia de $A$. catenella, constituye un factor relevante en la iniciación de las floraciones nocivas de esta especie (Seguel et al. 2010b). De las condiciones probadas en laboratorio la cepa creció mejor a una temperatura de $10^{\circ} \mathrm{C}$, fotoperiodo de luz: oscuridad de 16:08, 30 de salinidad y medio de cultivo L1, lográndose una tasa de crecimiento de $\mu=0,18$ y un máximo de abundancia celular de 3.788 células $\mathrm{mL}^{-1}$. Los resultados de tasas de crecimiento y abundancia celular fueron claramente inferiores a los obtenidos por 
otros autores. Por ejemplo, Navarro et al. (2006), Garrido et al. (2012) y Aguilera-Belmonte et al. (2013) cultivaron en laboratorio células vegetativas provenientes de floraciones algales, obteniendo en todos los casos sobre 5.200 células $\mathrm{mL}^{-1}$ con tasas de crecimiento superiores a $\mu=0,18$. Las diferencias en los resultados obtenidos pueden ser atribuibles a factores como: a) intensidad lumínica, ya que Navarro et al. (2006) y Aguilera-Belmonte et al. (2013) usaron $59,53 \mu \mathrm{mol} \mathrm{m} \mathrm{m}^{-2} \mathrm{~s}^{-1}$ y $65 \mu \mathrm{mol} \mathrm{m} \mathrm{m}^{-2} \mathrm{~s}^{-1}$ respectivamente, mientras que Garrido et al. (2012) utilizó una intensidad similar al presente estudio $\left(24 \mu \mathrm{mol} \mathrm{m} \mathrm{m}^{-2} \mathrm{~s}^{-}\right.$ ${ }^{1}$ ), b) tamaño del inoculo inicial, ya que iniciaron cultivos con 600 y 500 células mL $\mathrm{mL}^{-1}$ (Navarro et al. 2006, AguileraBelmonte et al. 2013), respectivamente, mientras que en el presente estudio los cultivos se iniciaron con un promedio de aproximadamente 200 células $\mathrm{mL}^{-1}$; c) tipo de cepa, los trabajos antes mencionados utilizaron células vegetativas provenientes de floraciones algales, a diferencia del presente estudio que se realizó con células provenientes de germinación de quistes de resistencia y d) lugar de origen de la cepa, los trabajos antes mencionados utilizan cepas provenientes de distintas localidades del mar interior del sur austral de Chile, mientras que en el presente trabajo las muestras de quistes fueron colectadas en la localidad de Punta Yenecura, Quellón.

Las curvas de crecimiento de temperatura, fotoperiodo y nutrientes muestran que la cepa estudiada alcanza un máximo solo después de 20 días de cultivo (3.200 células $\left.\mathrm{mL}^{-1}\right)$. Estos resultados difieren de lo descrito por Aguilera-Belmonte et al. (2010) quienes muestran que alcanza una máxima concentración (rango entre 11.000 y 52.000 células $\mathrm{mL}^{-1}$ ) entre los 10 a 12 días de cultivo para las cepas estudiadas. Por otra parte, Navarro et al. (2006) señalan que la cepa de Aysén alcanza una máxima concentración (29.460 células $\mathrm{mL}^{-1}$ ) a los 40 días de cultivo. Estos antecedentes demuestran que cada cepa de $A$. catenella cultivada en laboratorio, tiene requerimientos característicos, lo que explicaría en parte la variabilidad de la especie en su distribución espacial y temporal.

Las condiciones de salinidad de la columna de agua durante primavera-verano en el mar interior del sur de Chile varían entre 26 y 33 (Clément 1988, Iriarte et al. 2007), valores que están dentro del rango utilizado en el laboratorio (15-31). La respuesta observada de la cepa estudiada a variaciones en salinidad indica que sobrevive y crece en el rango probado en este trabajo. AguileraBelmonte et al. (2013) demostraron que A. catenella en experimentos combinados de temperatura y salinidad, crece hasta salinidades de 35, mostrando además, que en esta condición la especie presenta una alta toxicidad. En el presente estudio no se efectuaron análisis de toxicidad para cada tratamiento, sin embargo se realizó un análisis para conocer los rangos de toxicidad de la cepa. Los resultados mostraron que la cepa tiene toxinas del tipo GTX3 y GTX4 (3,14 y 1,15 fmol célula ${ }^{-1}$ respectivamente).

La cepa AC090610 QUE Q, incrementó su abundancia celular en $10 \mathrm{y} 15^{\circ} \mathrm{C}$, pero el tratamiento de $20^{\circ} \mathrm{C}$ no favoreció las tasas de crecimiento ni las propiedades ópticas de absorción. Estos resultados indican que, aunque la especie tiene un amplio rango de tolerancia en temperatura (Navarro et al. 2006), el incremento de temperatura no sería un factor determinante en un florecimiento. Molinet et al. (2003) también señalan que la especie se adaptaría a un rango amplio de temperaturas. Los resultados del presente trabajo muestran que en las condiciones probadas la cepa crece mejor a $10^{\circ} \mathrm{C}$, siendo esta temperatura inferior a la reportada como óptimo en la literatura para otras localidades (Navarro et al. 2006, Aguilera-Belmonte et al. 2013). Laabir et al. (2011) reportan en un estudio efectuado para la misma especie del Mediterráneo, que el mayor crecimiento se logra a 15 y $27^{\circ} \mathrm{C}$, indicando que la cepa estudiada muestra capacidades adaptativas en un amplio rango de condiciones.

Los fotoperiodos probados no muestran grandes diferencias en crecimiento y al parecer no es un factor relevante en el crecimiento de la cepa de estudio, pues las floraciones naturales ocurren justamente en verano, que corresponden a períodos de fotoperiodo largo. Otros estudios señalan que el rango adecuado para este parámetro es 14:10 y 16:08 (luz: oscuridad) (Gavin et al. 1997, Navarro et al. 2006).

De acuerdo a lo señalado por Collos et al. (2004) y Garrido et al. (2012), A. catenella tendría una estrategia de incorporación de nitrógeno $(\mathrm{N})$ como urea, amonio, nitrato o nitrito, demostrando que estos nutrientes pueden gatillar una floración y que la especie preferentemente tendría la capacidad de almacenar grandes cantidades de $\mathrm{N}$ antes de iniciar la división celular, explicando de esta manera la ocurrencia de floraciones algales nocivas (FAN). Los resultados de crecimiento en los distintos tratamientos de nutrientes muestran que la cepa ante una mayor disponibilidad ( $\mathrm{L} 1$ y L1/2) incrementa las tasas de crecimiento y división celular, mientras que en los tratamientos $\sin \mathrm{N}$ y $\mathrm{P}$ y el control (solo agua de mar) disminuye la tasa de crecimiento, lo que indica que se comporta en forma similar a cepas de células vegetativas de otras localidades de la misma especie (Garrido et al. 2012) 
Las múltiples interacciones de factores biológicos, climáticos y oceanográficos que favorecen el desarrollo de una FAN en ecosistemas marinos hasta ahora se entienden parcialmente. Molinet et al. (2003) y Navarro et al. (2006) sugieren posibles patrones de distribución espacial y temporal de esta especie, indicando que los factores más determinantes serían la temperatura y cambios en salinidad, entre enero-marzo. Este trabajo aporta antecedentes que un factor relevante, además de la temperatura y salinidad, sería la disponibilidad de nutrientes en la columna de agua, situación que favorecería el inicio de floraciones de A. catenella en el mar interior del sur de Chile.

\section{Agradecimientos}

Los autores agradecen a FONDEF por el financiamiento del proyecto FONDEF MR 10 I1004. Las muestras de quistes provienen del proyecto FONDEF MR07 I1010.

\section{LITERATURA CITADA}

Aguilera-Belmonte A, I Inostroza, JM Franco, P Riobo \& P Gómez. 2011. The growth, toxicity and genetic characterization of seven strains of Alexandrium catenella (Whedon and Kofoid) Balech 1985 (Dinophyceae) isolated during the 2009 summer outbreak in southern Chile. Harmful Algae 12: 105-112.

Aguilera-Belmonte A, I Inostroza, K Saez, JM Franco, P Riobo \& P Gómez. 2013. The combined effect of salinity and temperature on the growth and toxin content of four Chilean strains of Alexandrium catenella (Whedon and Kofoid) Balech 1985 (Dinophyceae) isolated from an outbreak occurring in southern Chile in 2009. Harmful Algae 23: 55-59.

Alves-de-Souza C, D Varela, F Navarrete, P Fernández \& $P$ Leal. 2008. Distribution, abundance and diversity of modern dinoflagellate cyst assemblages from southern Chile (43-54º S). Botanica Marina 51: 399-410.

Anderson DM, TJ Alpermann, AD Cembella, Y Collos, E Masseret \& M Montresor. 2012. The globally distributed genus Alexandrium: Multifaceted roles in marine ecosystems and impacts on human health. Harmful Algae 14: 10-35.

Bustamante J, A Jamett, A Yudelevich \& JL Cordova. 2003. AC29: the most abundant protein of Alexandrium catenella and its potential use in encystmente/excystment studies. Harmful Algae 2: 207-214.

Carrasco C \& N Silva. 2007. Distribución de temperatura, salinidad, oxigeno disuelto y nutrientes entre Puerto Montt y Boca del Guafo (CIMAR 12 Fiordos). Informes Preliminares. Taller de Resultados Crucero CIMAR 10 Fiordos, Octubre 2008, pp. 35-46. Comité Oceanográfico Nacional, Valparaíso.
Cassis D, P Muñoz \& S Avaria. 2002. Variación temporal del fitoplancton entre 1993 y 1998 en una estación fija del Seno Aysén, Chile ( $\left.45^{\circ} 26^{\prime} \mathrm{S} ; 73^{\circ} 00^{\prime} \mathrm{W}\right)$. Revista de Biología Marina y Oceanografía 37(1): 43-65.

Clément A. 1988. Oceanographic basis for managing the effects of noxious phytoplankton blooms on cage salmon aquaculture. Thesis M. Sc. MRM, Oregon State University, Corvallis, $52 \mathrm{pp}$.

Collos Y, C Gagne, M Laabir, A Vaquer, P Cecchi \& P Souchu. 2004. Nitrogenous nutrition of Alexandrium catenella (Dinophyceae) in cultures and in Thau Lagoon, Southern France. Journal of Phycology 40: 96-103.

Cordova JL \& I Müller. 2002. Use of PCR and partial sequencing of the large-subunit rRNA gene to identify Alexandrium catenella (Dinophyceae) from the South of Chile. Harmful Algae 1: 343-350.

Cox AM, DH Shull \& RA Horner. 2008. Profiles of Alexandrium catenella cysts in Puget Sound sediments and the relationship to paralytic shellfish poisoning events. Harmful Algae 7: 379-388.

Figueroa RI, I Bravo \& E Garcés. 2005. Effects of nutritional factors and different parental crosses on the encystment and excystment of Alexandrium catenella (Dinophyceae) in culture. Phycologia 44: 658-670.

Fuentes C, A Clément \& A Aguilera. 2006. Summer Alexandrium catenella bloom and the impact on fish farming, in the XI Aysén Region, Chile. In: International Society for the Study of Harmful Algae (ISSHA), XII ${ }^{\text {th }}$ International Conference on Harmful Algae, Copenhagen, pp.183-186.

Garrido C \& M Frangópulos. 2012. Does a relationship exist between the growth and toxicity of Alexandrium catenella (Dinoflagellata)? Anales del Instituto de la Patagonia 40(2): 155-158.

Garrido C, M Frangópulos \& D Varela. 2012. Effect of different nitrogen/phosphorus nutrient ratios on growth and toxin content of Alexandrium catenella (Dinoflagellata). Anales del Instituto de la Patagonia, Chile 40(2): 113-123.

Gavin K, Y Siu, MLC Young \& DKO Chan. 1997. Environmental and nutritional factors which regulate population dynamics and toxin production in the dinoflagellate Alexandrium catenella. Hydrobiologia 352: 117-140.

Guillard RRL \& PE Hargraves. 1993. Stichochrysis immobilis is a diatom, not a Chrysophyte. Phycologia 32: 234-236.

Guzmán L, I Campodónico \& M Antunovic. 1975a. Estudios sobre un florecimiento toxico causado por Gonyaulax catenella en Magallanes. IV.Distribución y niveles de toxicidad del veneno paralitico de los mariscos (Noviembre de 1972-Noviembre de 1973). Anales del Instituto de la Patagonia, Chile 6: 209-217.

Guzmán L, I Campodónico \& J Hermosilla. 1975b. Estudios sobre un orecimiento tóxico causado por Gonyaulax catenella en Magallanes. I. Distribución espacial y temporal de G. catenella. Anales del Instituto de la Patagonia, Chile 6: 173-183. 
Iriarte JL, HE Gonzalez, KK Liu, C Rivas \& C Valenzuela. 2007. Spatial and temporal variability of chlorophyll and primary productivity in surface waters of southern Chile (41.5-43 $\left.{ }^{\circ} \mathrm{S}\right)$. Estuarine, Coastal and Shelf Science 74: 471480 .

Laabir M, C Jauzein, B Genovesi, E Masseret, D Grzebyk, P Cecchi, A Vaquer, Y Perrin \& Y Collos. 2011. Influence of temperature, salinity and irradiance on the growth and cell yield of the harmful red tide dinoflagellate Alexandrium catenella colonizing Mediterranean waters. Journal of Plankton Research 33(10): 1550-1563.

Lembeye G, N Marcos, A Sfeir, C Molinet, F Jara,A Clément \& X Rojas. 1998. Seguimiento de la toxicidad en recursos pesqueros de importancia comercial en la X y XI región. Informe Final, Universidad Austral de Chile. Fondo de Investigación Pesquera. Proyecto FIP IT/97-49: 1-86.

Lembeye G. 2006. Florecimientos algales nocivos en aguas australes. En: Silva N \& S Palma (eds). Avances en el conocimiento oceanográfico de las aguas interiores chilenas, Puerto Montt a Cabo Hornos, pp. 99-103. Pontificia Universidad Católica de Valparaíso / CONA, Valparaíso.

Mardones J, A Clément, X Rojas \& C Aparicio. 2010. Alexandrium catenella during 2009 in Chilean waters, and recent expansion to coastal ocean. Harmful Algae News 41: 8-9.

Matsuoka K \& Y Fukuyo. 2000. Guía técnica para el estudio de quistes de dinoflagelados actuales, $30 \mathrm{pp}$. WESTPACHAB/WESTPAC/IOC, Unesco, Paris.

Molinet C, A Lafon, G Lembeye \& C Moreno. 2003. Patrones de distribución espacial y temporal de floraciones de Alexandrium catenella (Whedon \& Kofoid) Balech 1985, en aguas interiores de la Patagonia noroccidental de Chile. Revista Chilena Historia Natural 76: 681-698.

Muñoz P, S Avaria, H Sievers \& R Prado. 1992. Presencia de dinoflagelados tóxicos del género Dinophysis en el seno de Aysén, Chile. Revista Chilena Historia Natural 27(2): 187212.
Navarro JM, ME Muñoz \& AM Contreras. 2006. Temperature as a factor regulating growth and toxin content in the dinoflagellate Alexandrium catenella. Harmful Algae 5: 762-769.

Seguel M, A Sfeir \&V Albornoz. 2006. Distribución de quistes de Alexandrium catenella y Protoceratium reticulatum (Dinoflagelados) en sedimentos provenientes de la Región de Los Lagos $\left(41^{\circ} 25^{\prime}-43^{\circ} 08^{\prime}\right.$ Lat S). Informes Preliminares, Crucero CIMAR11 Fiordos, CONA, pp. 51-57.

Seguel M, A Sfeir, V Albornoz, M Gangas, C Molinet \& P Díaz. 2010a. Distribución de los quistes de Alexandrium catenella y Protoceratium reticulatum (DINOPHYCEAE) en la Región Sur-Austral de Chile. Ciencia y Tecnología del Mar 33: 59-70.

Seguel M, A Sfeir \& V Albornoz. 2010b. Distribucion de quistes de Alexandrium catenella y Protoceratium reticulatum en la zona comprendida entre Puerto Montt y la Boca del Guafo. En: Resultados Crucero CIMAR 10 Fiordos (17 de agosto al 3 de septiembre y 8 al 26 de noviembre 2004). Informes preliminares, pp. 71-76. <http:/ /www.shoa.cl/n_cendhoc/productos/cimar10/resumenes/ pdf/6_seguel.pdf>

Uribe JC, S Oyarzún \& V Latorre. 2010. Alexandrium catenella (Whedon \& Kofoid) Balech, 1985, in Magellan waters, Chile. Anales del Instituto de la Patagonia, Chile 38(1): 103-110.

Utermöhl H. 1958. Zurvervollkommnung der quantitativen Phytoplankton-Methodik. Mitteilungen der Internationale Vereinigung für Theoretische und Angewandte Limnologie 9: 1-39.

Varela D, J Paredes, C Alves-de-Souza, M Seguel, A Sfeir \& M Frangopulos. 2012. Intraregional variation among Alexandrium catenella (Dinophyceae) strains fron Southern Chile: Morphological, toxicological and genetic diversity. Harmful Algae 15: 8-18. 